\title{
An analysis of popularizing the electric vehicle
}

\author{
Sun Yuechao \\ College of mechanical and electrical engineering , Lingnan Normal University ,Zhanjiang 524048, \\ China \\ yuechaosun@sina.com
}

\begin{abstract}
Key words: electric vehicle; popularization; infrastructure construction
Abstract: Popularizing the electric vehicle is the main means of settling the environmental and energy crisis. The key constraints of electric vehicle's popularization are presented in this paper. The problems are mainly embodied in four aspects: the power needs to be improved at technology level, the cost of electric cars should be decreased to mini quite level in economy, the construction of charging stations are supposed to be unified especially the charging generator and charge couple, and the government is require to introduce policies to support and encourage research and development, and formulate preferential policies to encourage consumption of the electric vehicle.
\end{abstract}

\section{Introduction}

Automobile exhaust is the main source of the air pollution which caused the dust-haze and photochemical smog in our country. It is Obvious to all that automobile exhaust do a lot of harm to the human's Living environment.Reducing the harmful gases emission and creating green traffic are urgently required. During the spring of the 2013 and 2014, hazy weather appeared among many cities, especially in Beijing the weather last 6 to 10 days, and the concentration index table of PM2.5 is extra high than usual. Automobile exhaust contributed the rate as high as 25 percents to it. Moreover, with the depletion of oil resources, energy crisis become more and more serious, countries all over the world are getting involved in a smokeless energy war.So popularizing the electric vehicle is a primary method to settle the problem between the environment and energy request in the future. The research and practice shows that the traditional fuel cars transform to electric vehicle which have high efficiency and low emission will be the mainstream direction of the new energy car. As long as the improvement of the technique, economic investment, building of public infrastructure and support policies, the electric vehicle will be popularized soon.

\section{The introduction of electric vehicle}

The electric vehicle is a car whose power system is the electromotor drived in all or in part by electricity. Usually, the electric powers are fuel cell, solar cell and other kinds of batteries. We usually divide them into three categories such as Battery electric vehicle, Fuel-cell hybrid vehicle, Hybrid Electric Vehicle. Battery electric vehicle is also called secondary battery electric vehicles or full electric vehicle. Fuel-cell hybrid vehicle is called composite power electric cars. The definition of the fuel-cell hybrid vehicle should be paid more attention, the Electric Vehicle Technology Committee which belongs to the Internatonal Electrical Committee offer the definition of the fuel-cell hybrid vehicle is the car that own two or more storages and energy converter as the driving energy, and at least one of them can provide the electricity. Strictly, most fuel-cell hybrid vehicles are belonged to composite power electric car. In order to extrude the feature of the electric vehicle, this kind of hybrid electric vehicle is often called as fuel-cell hybrid vehicles. The car which own both internal combustion engine and electric motor is regard as composite power car. The electrombiles are named by their batteries, such as hydrogen cell car, accumulator car, solar electric car, acid battery car and nickel hydrogen battery car ${ }^{[1]}$. 


\section{Full electric vehicle}

Full electric vehicle treat the battery (for instance, lead acid battery, ni-cd batteries, ni-mh battery and lithium-ion battery) as power, regard accumulator as storage unit and use electricity as energy. Full electric vehicle is mainly composed of electrical drive sub-system, energy sub-system and assistant sub-system. The electrical drive sub-system includes electronic controller, power converter, electric motor and mechanical transmission device. Energy sub-system consists of energy source, energy unit and energy control unit. The assistant sub-system contains power-assisted steering unit, temperature control unit and auxiliary power supply unit. Full electric vehicle have an advantage in no gas emission and no rely on oil, while because of the low energy density and low power density refer to the oil, full electric vehicle own a limited distance. The high performance power battery, (for example lithium-ion battery), has gain a great progress recently. But the input cost is too much in the initial stage. The full electric vehicle is mainly used in local community.

\section{Hybrid electric vehicle}

Hybrid electric vehicle adopts the internal combustion engine and electric motor as power, the oil and accumulator as energy. Accumulator can be charged by the generator drived by internal combustion engine. Hybrid electric vehicle cars on the market are optimized controlled between energy sources according to the driving condition. Hybrid electric vehicle car is classified into three classes: cascade, parallel, parallel and series. The cascade type put motor, generator and engine together in a series. The power unit is made of the cascade type. Engine drives the generator to provide electricity. The electricity is conveyed to battery or motor by controller. The vehicle is actuated by the motor through the speed change mechanism. The parallel type put engine and motor together in parallel to drive the car. Engine and motor are separated into two systems which can provide torque for vehicle independently. They can actuate the car together or alone in different driving condition. The parallel and series type vehicle which consist of engine, generator and driving motor unites and the characteristics of the cascade and parallel type. Compare to the full electric vehicle, Hybrid electric vehicle is lighter, the driving distance and the dynamic property is equal to the traditional car, and more comfortable. Compared with the internal combustion engine car, the Hybrid electric vehicle guarantee the engine works in the optimal area to reduce the pollution. It can change the motor model to realize the zero pollution in the commercial district, recycle the energy produced by slow down or braking. Lower the energy consumption and environmental pollution.

\section{Fuel-cell hybrid vehicle}

Fuel-cell hybrid vehicle equips the electric motor as its power, fuel cell is used as energy converter and hydrogen is the main energy source. Due to the Fuel-cell hybrid vehicle is in the early stages of research, so the construction of the fuel-cell hybrid vehicle is different with accumulator. The accumulator can lower the cost and the power requirement of the fuel cell through the recovery of the barking energy. Although fuel-cell hybrid vehicle has a bright future, it has not accomplished industrialization. The cost remain high, the reliability and working life of the fuel cell should be improved yet. The filling hydrogen infrastructure needs to be set up and systematically, the source of the hydrogen and the supply chain also needs to be implemented.

\section{An analysis on bottleneck of popularizing the electric vehicle}

\section{Technique problem}

Our research and development ability has been substantially enhanced through the 863 plan during these years, technical difficulties are overcome step by step, detection means are more and more useful. The overall technical reach or close to the international advanced level, while part of 
skill have reached it. For example, double CAN bus controller network system, digital four-quadrant vector control in induction motor and permanent magnet motor, distributed and web-based battery management and smart high-voltage safety management system and so on, Which are in the lead in the current international. So, some experts say that there are not any technical obstacles in popularizing the electric vehicle recently. Others believe that many skill problems have not been solved yet. The working life of the battery is not long enough while change it cost too much. Localization components have not been accomplished. Key elements need to be imported, and fast battery charging in the low temperature is not overcome perfectly. Additionally, the research of electric vehicle are laboratory technique, critical technical index which can not ensure the uniformity of experimental dates and real dates because lack of quality control when working on the complex operation practical condition. Although some critical skills have been worked out, it doesn't mean the popularization of the electric vehicle are coming soon. Vehicle is integrated, complex system. The standard, such as computer control, motor and transmission quality, become more seriously when it come to full electric vehicle. Only if critical technique, traditional skill, key elements and traditional elements have been improved, we can develop the advanced electric vehicle which can be marketed. This kind of change produced by car revolution in energy system and vehicle industry chain which can not be adopt within a short period to all countries. It remains controversy.

\section{Economic problem}

Full electric vehicle are free from the rising up of the oil prize. But the change of the power system (the extra expenditure for motor controller, battery) make the cost higher, hence, full electric vehicle become expensive. The current commissioning and partial popularization in many countries' shows: the mini electric vehicles include low-performance two-wheel vehicle are popular in the industrialization, while the high-performance are designed to have a long distance and large speed requirements, so increasing body weight and the costing, motor power and battery capacity required is relatively enhanced, economic decline as a consequence. In this circumstance, it is not wise to buy the exorbitant electrical car without the financial subsidies when the traditional car is progressing in energy-saving technology. And this is one of the key problems in the e-vehicles' generalization. With the reduction of the battery cost and increasing production of the e-vehicle, the prize will be lower. Takeshi Fujimoto draw up a plan that unite the car industry, motor industry and universities to study the high-performance, low-prize battery charging technique. So that the high-performance e-vehicles' prize equal to the mini-car. Then operating economy of the e-vehicle will be more improved.

\section{Infrastructure problem}

The network of charging station, vehicle maintenance, all kinds of battery selling and vehicle service are included to form the full electric vehicle infrastructure. It is critical to build a certain number of public charging station, special cable and socket to extend the mileage and accomplish the industrialization of the e-vehicle. The infrastructure construction should be planed by the local government, invest by the power station and power supply company. Independent run by charging company and the profits should be not less than filling station. We can build dozens of charging station to facilitate the taxis, private cars, commercial vehicles. Bus companies can also build their own charging station in the terminal, the starting point station, charging for the bus lines provide service. Sanitation trucks can be charged in their own companies, private cars can be charged at their homes.

Then the problem of electric power supply exits. Some experts hold that the electric power construction has been improved greatly and installed capacity increased a lot in recent years. The generator we built will produce the power more than we need in next one or two years. If we modify the buses, taxis, private cars, sanitation trucks, commercial vehicles and the original fuel vehicles in the urban area, into full electrical vehicles. By making use of the low power price in the 
night to charge the vehicle we can not only save the energy, but also minimize the difference between the supply peak and the valley. Now the car company and grid company began to sit together to discuss the cooperation. The grid company provides the standard accumulator, use the valley electricity to charge the accumulators, then lend out them to e-vehicle or bus companies. In 2006, BYD shanghai research and development center build the first charging station for e-vehicle, and had been tested. Soon, internal vehicle charging stations have been built in Beijing, xi' an and Shenzhen. The state grid company have not only studied on the e-vehicle battery, vehicle's modification, demonstration, but also built the charging station in Olympic Arena and World Expo venue to unify the specification so that the production of the charging devices and sockets can be standard. And then perfect the construction of the internal charging network, the mating providing-charging facilities for the buses, taxis or other vehicles. Some experts consider that full e-vehicle is suitable to the French whose nuclear power is adequate. Because nuclear power station can provides electricity constantly. While in our country nuclear power ratio is very small, we are still lack of the electricity.

\section{Policy support}

Full electrical vehicle needs the government's support, market launch stage created by policy to speed up the commercialize process because of the issues on the technique, running economy and infrastructure construction. It is consist of four stages: demonstration publicity campaign--- a large demand by the government---quantity production--- government departs from the industry. Government's support policy concentrate on three links: first is the research link, country should set out a special fund to help and unite the automobile enterprises, cell producers and research \& development units together to build a research and development platform, come into being a binding mode of government, industry, academia and research. Concentrate the funds and facilities to accelerate the research process. Our country has done more successful in this regard. Second is the market link, take other countries' experience on developing the high-tech industry as a reference. Build a complete Tax Subsidy Policy for example: free the road maintenance fee, purchase tax and import taxes and levy the fuel taxes. In this respect, America and Japan have already done before, but we haven't. Third is the appliance link, set out the mating preferential policy including provide the free parking spaces, issue formal operating licenses, build the charging places to encourage the e-vehicle consumption and driving environment. We have been exploring the ways actively now.

\section{Conclusion}

We human beings are facing the growing worsening reality such as environmental pollution, global warming and energy security. Energy-saving and emission reduction become the strategic direction during the vehicle industry transformation. Since China has become the biggest auto sales and producer in 2009, we set a goal of making China as the powerful country in automobile industry. So it is urgent to study the new energy vehicles. Popularizing the e-vehicle is the main measure to solve the energy and environmental problems and to become powerful country in automobile.

But now we face the issues on technical problem, investment problem, infrastructure problem and the lack of policy in popularizing the e-vehicle. We believe the key issues will be solved soon with the government's support. At that time the cost of e-vehicle will be reduce, driving distance will be longer, after service is guaranteed and it's easy to charge the vehicle. Then popularization of electrical vehicle is done.

\section{References}

[1] Gong Jun. The motor technology and applications of new energy vehicle [M].Shanghai: Shanghai Science and Technology Press, 2012 
[2] Zhao Lijun, Tong Qinzhi. The structure and principle of electric vehicle [M].Beijing: Peking University Press, 2012

[3] Zhao Lijun. The test and evaluation of electric vehicle [M]. Beijing: Peking University Press, 2012

[4] Wang Zhenpo, Sun Fengchun. The battery power system and application technology of

Electric vehicle [M].Beijing: Mechanical Industry Press, 2012

[5] Li Xiangzhe, Su Fang, Lin Daoyong. The power supply system of electric vehicle [M].Beijing: Chemical Industry Press, 2012

[6] Ishikawa Kenji; Kang Longyun, Yu Kaijiang translate. New energy vehicle technology and the future: electric vehicles, hybrid cars, new fuel vehicles [M].Beijing: Science Press, 2012

[7] Gianfranco Pistoia. The Battery Application Technology: from the portable electronic device to an industrial product [M].Beijing: People Post Press, 2012

[8] Wang Zhenpo, Jia Yongxuan. The blueprint of electric cars [M].Beijing: Mechanical Industry Press, 2011

[9] Hoeijmakers M J, Ferreira J A. The electric variable transmission[J]. IEEE Trans on Indus Appl, 2006, 42 (4): 1092-1100.

[10] Chan C C, Bouscayrol A, Chen K. Electric, hybrid and fuel cell vehicles Architectures and modeling [J]. IEEE Trans on VehicularTechnology, 2010, 59(2): 589-598 